\title{
Antithrombin III as predictor of liver reserve: A new parameter to improve the results of mechanical circulatory support therapy
}

\author{
Gabriele Di Giammarco, MD, and Daniele Marinelli, MD
}

From the Department of Cardiac Surgery, University G. D'Annunzio, Chieti, Italy. Disclosures: Authors have nothing to disclose with regard to commercial support.

Received for publication Feb 12, 2017; accepted for publication Feb 15, 2017; available ahead of print March 30, 2017.

Address for reprints: Gabriele Di Giammarco, MD, Department of Cardiac Surgery, University G. D'Annunzio, Via dei Vestini 66100, Chieti, Italy (E-mail: gabriele.digiammarco@unich.it).

J Thorac Cardiovasc Surg 2017;153:1383

$0022-5223 / \$ 36.00$

Copyright (c) 2017 by The American Association for Thoracic Surgery

http://dx.doi.org/10.1016/j.jtcvs.2017.02.049

The prevention of end-organ dysfunction is among the most important goals of mechanical circulatory support (MCS) therapy.

Although the relationship between heart and kidney function is well studied, the role of liver function in the setting of cardiac failure is less known. ${ }^{1,2}$ The article by Hoefer and colleagues $^{3}$ clarifies the role of liver reserve and dysfunction in the setting of extracorporeal membrane oxygenation implantation and the chance to predict it by monitoring antithrombin III activity levels.

Hoefer and colleagues ${ }^{3}$ demonstrate that acute liver failure (ALF), defined using the King's College Criteria, is related to a high mortality rate in patients undergoing venoarterial extracorporeal membrane oxygenation implantation. The in-hospital mortality rate in this group of patients is reported to be $88.9 \%$. Moreover, use of ALF prediction to better select MCS candidates in the aim to improve survival is an important point in the setting of limited health care system resources.

The same authors ${ }^{3}$ demonstrate that using a simple laboratory test like antithrombin III is possible to predict with a high level of sensitivity and specificity $(81 \%$ and $89 \%$, respectively, with a positive predictive value of $72 \%$ for an antithrombin III activity cutoff equal to or lower than $59.5 \%$ ) the development of ALF after MCS.

Finally, liver dysfunction may be responsible of hemorrhage or thromboembolism due to the unpredictable effect of anticoagulation during MCS therapy. ${ }^{4}$ In this view, the chance to predict liver function before MCS implantation could assume a fundamental role to treat more aggressively any coagulation disorders in patients with lower preoperative antithrombin III levels.

A main limitation of the study is that patients undergoing MCS implantation in acute decompensated heart failure may already display different degrees of liver dysfunction that can be related to both reduced arterial perfusion and venous congestion. Consequently, little can be done for

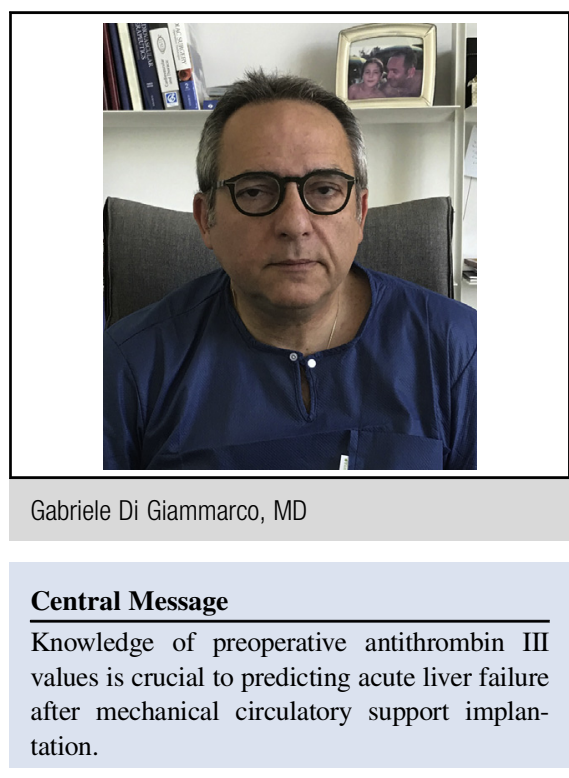

See Article page 1374.

these patients to reduce the risk of death and ALF. However, routine measurement of antithrombin III values in the setting of chronic heart failure can potentially represent a marker of possible liver dysfunction. This evidence can lead to optimized timing of MCS implantation. Therefore, cardiologists and cardiac surgeons working in the field of heart failure should be strongly sensitized toward routine monitoring of antithrombin III levels.

\section{CONCLUSIONS}

This important study introduces what should be considered a very important marker of liver function and reserve in the setting of MCS therapy.

\section{References}

1. Metra M, Cotter G, Gheorghiade M, Dei Cas D, Voors AA. The role of the kidney in heart failure. Eur Heart J. 2012;33:2135-43.

2. Naschitz JE, Slobodin G, Lewis RJ, Zuckerman E, Yeshurun D. Heart diseases affecting the liver and liver diseases affecting the heart. Am Heart J. 2000;140: $111-20$.

3. Hoefer J, Ulmer H, Kilo J, Margreiter R, Grimm M, Mair P, et al. Antithrombin III is associated with acute liver failure in patients with end-stage heart failure undergoing mechanical circulatory support. J Thorac Cardiovasc Surg. 2017;153:1374-82.

4. Susen S, Rauch A, Van Belle E, Vincentelli A, Lenting P. Circulatory support devices: fundamental aspects and clinical management of bleeding and thrombosis. $J$ Thromb Haemost. 2015;13:1757-67. 